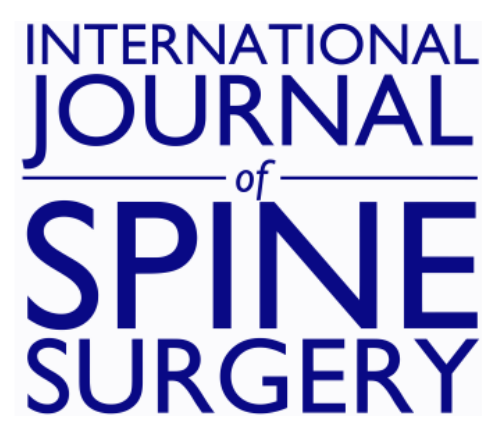

\title{
An Analysis of Implant Retention and Antibiotic Suppression in Instrumented Spine Infections: A Preliminary Data Set of 67 Patients
}

KRISHN KHANNA, ABHINAV JANGHALA, DAVID SING, BRENNAN VAIL, GRIGORIY ARUTYUNYAN, BOBBY TAY and VEDAT DEVIREN

Int J Spine Surg 2018, 12 (4) 490-497

doi: https://doi.org/10.14444/5060

http://ijssurgery.com/content/12/4/490

This information is current as of April 25, 2023.

Email Alerts Receive free email-alerts when new articles cite this article. Sign up at: http://ijssurgery.com/alerts

The International Journal of Spine Surgery 2397 Waterbury Circle, Suite 1, Aurora, IL 60504, Phone: +1-630-375-1432 


\title{
An Analysis of Implant Retention and Antibiotic Suppression in Instrumented Spine Infections: A Preliminary Data Set of 67 Patients
}

\author{
KRISHN KHANNA, MD, ABHINAV JANGHALA, MD, DAVID SING, MD, BRENNAN VAIL, MD, \\ GRIGORIY ARUTYUNYAN, MD, BOBBY TAY, MD, VEDAT DEVIREN, MD \\ Department of Orthopaedic Surgery, University of California, San Francisco, San Francisco, California
}

\begin{abstract}
Background: It is unclear whether patients can be taken off suppressive antibiotics with infected retained instrumentation. This study aimed to retrospectively analyze the perioperative course and antibiotic regimen that led to the clinical intervention of patients with infected spinal instrumentation.

Methods: Consecutive adult patients with spine instrumentation who suffered surgical site infections (SSI) requiring debridement were retrospectively analyzed. The patients were grouped into 4 cohorts based on their clinical intervention: removal of instrumentation, reinstrumentation, retention of instrumentation with continued antibiotic suppression, and retention of instrumentation with no antibiotic suppression. Patient factors, infection factors, debridement, and antibiosis were compared.

Results: Of the 67 patients with SSI after spine surgery and instrumentation, $19(28 \%)$ had their instrumentation removed, $6(9 \%)$ had their instrumentation exchanged, $25(37 \%)$ had their instrumentation retained and were on antibiotic suppression, and $17(25 \%)$ had their instrumentation retained without any suppression. Those who had their instrumentation removed had a later presentation of their infection averaging 85 days (range 6-280 days) postoperatively. There was an earlier presentation for those who retained their implants, with suppression averaging 19 days (range 9-39) and no suppression averaging 29 days (range 6-90 days) post operatively $(P<.001)$.

Conclusions: None of the patients with retained instrumentation without suppression had recurrence of infections after long-term follow-up. Lifelong antibiotic suppression may not be required with SSI that present early after early aggressive debridement. Patients with infections detected later are difficult to treat without removal of their original instrumentation.
\end{abstract}

Clinical Relevance: This study presents the outcomes of surgical and antibiotic factors in patients with infected spinal instrumentation.

Complications

Keywords: surgical site infection, spinal instrumentation, antibiotic suppression

\section{INTRODUCTION}

Infections of surgical wounds remain one of the most common adverse events in hospitalized patients in the 21st century, only behind adverse drug reactions. ${ }^{1}$ Surgical site infections (SSI) alone cost the US healthcare system $\$ 10$ billion annually ${ }^{2}$ with over $300 \%$ increases in cost per patient compared to those without SSI. ${ }^{3,4}$ Costs stem not only from repeat surgical procedures, increased hospital stays, and poor patient outcomes but also from the cost of long-term antibiotics and the side effects from these medications. $^{3}$

SSI after spine surgery is particularly challenging, leading to devastating complications and worse outcomes in patients. ${ }^{3,5,6}$ The incidence of SSI after spine procedures range from $2.9 \%$ to $15 \%{ }^{3,7,8}$ This number is higher if only instrumented surgeries are considered. The majority of the evidence on infection surrounding implants comes from arthroplasty literature $;^{9-13}$ however, the principles remain applicable. The major surgical decision in periprosthetic joint infections relies on the timing of infection: if presenting acutely, then the implants may be debrided and retained. However, a delayed presentation warrants a staged removal of the implants, as the bacteria have transitioned from their planktonic state to a biofilm, preventing debridement from completely eradicating the infection. ${ }^{10}$ 
However, SSI with instrumentation presents a unique problem to the spine surgeon. ${ }^{14-18}$ A staged removal of implants is often not possible, as the stability of the spine must be maintained with instrumentation until fusion. ${ }^{17}$ Even once fusion is achieved, there is evidence demonstrating worsening of deformity after the removal of instrumentation. ${ }^{15}$ Thus, the treatment options are limited to removing the instrumentation after fusion, reinstrumenting the spine, or retaining the instrumentation with antibiotic suppression. There is no published algorithm or consensus statement in spine literature that dictates the surgical decision making for infected spinal instrumentation.

The optimal antibiotic regimen for patients who are retaining their spinal instrumentation despite SSI is not well understood and is often left to infectious disease (ID) consultants to determine. Recommendations from ID consultants at our institution often consist of a course of long-term IV antibiotics followed by lifelong oral suppression. The basis for this regimen comes from the idea that the implants are seeded and will continue to be a source of infection for the duration they are left in. However, the decision of the duration of IV antibiotics and subsequent oral antibiotics is not one to take lightly and without input from the surgeon. Often, the surgeon is the one who has the closest follow-up with the patient and also witnesses the side effects from these nonbenign medications. Although there are studies examining the treatments for spinal implant infections, ${ }^{19-24}$ the literature does not answer whether lifelong antibiotics are necessary for retained spinal instrumentation after SSI.

This study aims to retrospectively analyze the perioperative course and antibiotic regimen of patients who suffered an SSI after spinal instrumentation. This preliminary data shed light on whether lifelong antibiotics are necessary for suppression after infection of an instrumented spine. It also aims to present trends in this retrospective analysis of these infections that may aid in developing a future algorithm of when to remove, exchange, or retain infected spinal instrumentation.

\section{MATERIALS AND METHODS}

An institutional review board for this retrospective analysis was obtained (University of California, San Francisco, Institutional Review Board 1516807). Consecutive adult patients with SSI after spine surgery at a single institution from 2007 to
2013 were retrospectively analyzed. Inclusion criteria included adult patients over the age of 18 with spine instrumentation who suffered an SSI requiring surgical irrigation and debridement. An SSI was defined as a revision spine surgery for SSI with culture positive drainage or tissue samples.

The patients were grouped into four cohorts based on their clinical intervention: removal of instrumentation, reinstrumentation, retention of instrumentation with continued antibiotic suppression, and retention of instrumentation with no antibiotic suppression. The surgical decision making was based purely on the surgeon's preference, with no particular algorithmic approach, as there is none defined in the literature. Some guiding principles included the index revision performed on patients with wound findings consistent with underlying infection. The decision to retain or remove instrumentation was based largely on the severity of the infection at initial debridement, the response to the prior surgical debridement, and the probability of the stability of the spine at the time of debridement. The response to the prior surgical debridement was defined both by the superficial appearance of the wound after the most recent surgery and by the trend in inflammatory markers. Being off of antibiotic suppression was defined as not being on any antibiotic therapy at the time of the most recent surgical follow-up. Follow-up times were defined as the time between the day of surgery and the most recent follow-up date.

Four different domains were compared between the four cohorts: patient characteristics, infection characteristics, debridement characteristics, and antibiosis characteristics. Univariate analysis was conducted between the four cohorts to determine which variables were different.

\section{STATISTICAL METHODS}

Descriptive statistics were performed on the data. An analysis of variance $F$ test was used to test continuous variables for significance. The Fisher exact test was used to test discrete variables. A $P$ value of .05 was considered statistically significant.

\section{RESULTS}

Of the 67 patients with SSI after spine surgery and instrumentation, 19 (28\%) had their instrumentation removed, $6(9 \%)$ were reinstrumented, 25 $(37 \%)$ had their instrumentation retained and were 
Table 1. Patient characteristics.

\begin{tabular}{|c|c|c|c|c|c|c|}
\hline & $\begin{array}{l}\text { Hardware } \\
\text { Removed }\end{array}$ & Reinstrumented & $\begin{array}{l}\text { Hardware Retained } \\
\text { with Suppression }\end{array}$ & $\begin{array}{l}\text { Hardware Retained } \\
\text { without Suppression }\end{array}$ & $P$ Value & Test \\
\hline Total no. of patients & 2 & 6 & 25 & 17 & & \\
\hline Average age: $n$ (SD) & $60.9(10.4 \%)$ & $64.2(19.6 \%)$ & $61.9(14.1 \%)$ & $61.8(14.4 \%)$ & .969 & ANOVA $F$ test \\
\hline Female gender: $n(\%)$ & $12(63.2 \%)$ & $3(50 \%)$ & $16(64 \%)$ & $13(76.5 \%)$ & .668 & Fisher exact \\
\hline ASA score: $n(\%)$ & & & & & .5 & Fisher exact \\
\hline 1 & $1(5.3 \%)$ & $0(0 \%)$ & $1(4 \%)$ & $0(0 \%)$ & & \\
\hline 2 & $13(68.4 \%)$ & $3(50 \%)$ & $13(52 \%)$ & $7(41.2 \%)$ & & \\
\hline 3 & $5(26.3 \%)$ & $3(50 \%)$ & $11(44 \%)$ & $10(58.8 \%)$ & & \\
\hline $\begin{array}{l}\text { Mean length of follow-up } \\
\text { in days: } n \text { (SD) }\end{array}$ & $1155.7(767.5)$ & $1358.5(767.6)$ & $791.2(712.7)$ & $1555.4(938)$ & .026 & ANOVA $F$ test \\
\hline
\end{tabular}

Abbreviations: ANOVA, analysis of variance; ASA, American Society of Anesthesiologists.

on antibiotic suppression, and $17(25 \%)$ had their instrumentation retained without any suppression. Those without antibiotic suppression have the longest follow-up, averaging approximately 4 years off of antibiotics (range 293-2823 days) with no need for further intervention, compared with other cohorts.

All patients who had their instrumentation removed or exchanged remained on antibiotics until that surgery except for 1 patient who was off of antibiotics for 1 year but had a recurrence of drainage requiring implant removal. Patients with their instrumentation removed had their instrumentation implanted for an average of 503 days (range 26-2303 days). Patients who were reinstrumented had their original instrumentation implanted for 343 days (range 21-686 days).

The patients without suppression discontinued their antibiotics because they were either prescribed short antibiotic courses, had gastrointestinal side effects, or were advised to do so by the infectious disease consultant. Fourteen of the 67 patients had documented side effects to antibiotic therapy: 11 complained of gastrointestinal side effects, 1 of dizziness, and 2 of rash.

Three of the 6 patients who were reinstrumented remain on oral antibiotic suppression. Three of the 6 are no longer on suppression antibiotics and have an average of more than 5 years of follow-up off of antibiotics (range 1364-2659 days) with no need for further intervention.

Patient characteristics (Table 1), including age, gender, and American Society of Anesthesiologists score, did not vary significantly between the three groups. Figure 1 is a graphical representation of the clinical outcomes versus the number of instrumented levels.

Those who had their instrumentation removed or were reinstrumented had a later presentation of their infection, with removal averaging 85 days (range 6-280 days) and reinstrumentation averaging 123 days (range 4-323 days) postoperatively. There was an earlier presentation for those who retained their implants, with suppression averaging 19 days (range 9-39) and no suppression averaging 29 days (range 6-90 days) postoperatively. The number of polymicrobial infections between the cohorts trended toward significance $(P=.077)$, with those with instrumentation removed or reinstrumentation having over twice as many patients with polymicrobial infections than the cohorts with their instrumentation retained (Table 2).

Patients with retained instrumentation without suppression had a single debridement, and there was a significantly greater number of debridements in those with instrumentation removed and exchanged (Table 3). The probability of retaining instrumentation dropped from $63 \%$ after the first debridement to $26 \%$ after the second and $17 \%$ after the third, and no patients were able to retain instrumentation if they had 4 or more debridements (Figure 2). No significant differences emerged when examining intraoperative interventions (Table 3).

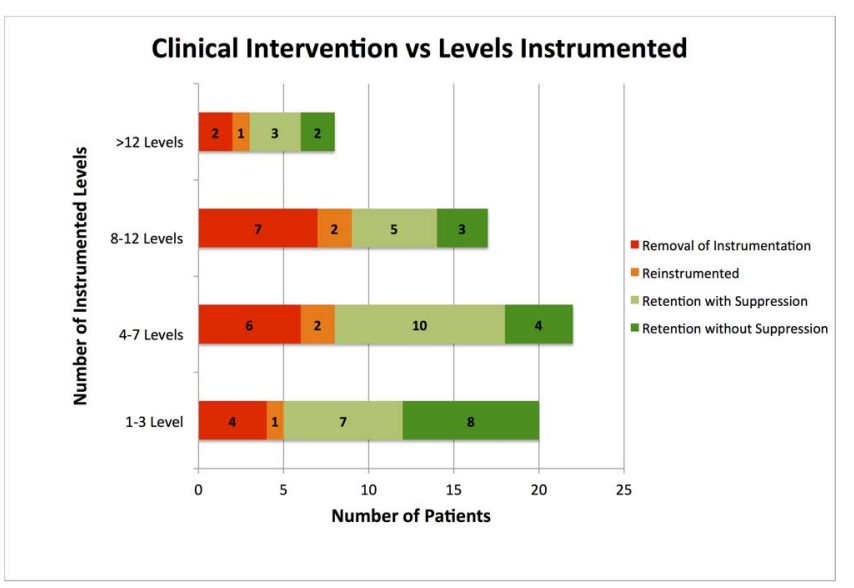

Figure 1. Graphical representation of the clinical intervention relative to the number of instrumented levels. 
Khanna et al.

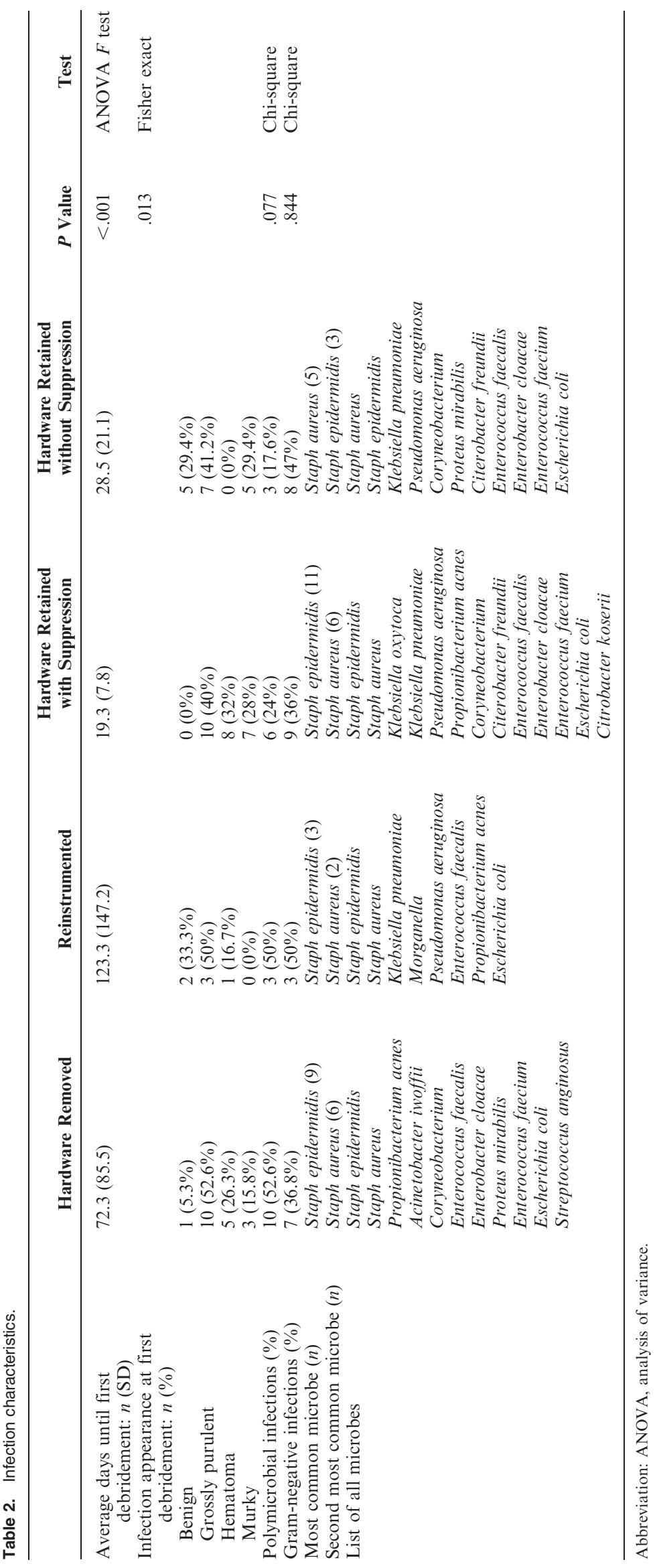

Downloaded from http://ijssurgery.com/ by guest on April 25, 2023 


\begin{tabular}{|c|c|c|c|c|c|c|}
\hline & $\begin{array}{c}\text { Hardware } \\
\text { Removed }\end{array}$ & Reinstrumented & $\begin{array}{l}\text { Hardware } \\
\text { Retained with } \\
\text { Suppression }\end{array}$ & $\begin{array}{c}\text { Hardware } \\
\text { Retained } \\
\text { without } \\
\text { Suppression }\end{array}$ & $P$ Value & Test \\
\hline Average number of debridements: $\mathrm{n}$ (SD) & $2.8(1.4)$ & $1.8(0.8)$ & $1.4(0.6)$ & $1(0)$ & $<.001$ & ANOVA $F$ test \\
\hline Debridement below fascia during first debridement: $\mathrm{n}(\%)$ & $18(94.7 \%)$ & $6(100 \%)$ & $25(100 \%)$ & $15(88.2 \%)$ & .326 & Fisher exact \\
\hline Debridement below fascia during any debridement: $\mathrm{n}(\%)$ & $19(100 \%)$ & $6(100 \%)$ & $25(100 \%)$ & $15(88.2 \%)$ & .166 & Fisher exact \\
\hline Use of bacitracin: $\mathrm{n}(\%)$ & $10(62.5 \%)$ & $2(33.3 \%)$ & $8(32 \%)$ & $4(23.5 \%)$ & .122 & Fisher exact \\
\hline Use of iodine: $\mathrm{n}(\%)$ & $3(18.8 \%)$ & $0(0 \%)$ & $2(8 \%)$ & $2(11.8 \%)$ & .633 & Fisher exact \\
\hline Use of Dakin's solution: n (\%) & $10(62.5 \%)$ & $2(33.3 \%)$ & $9(36 \%)$ & $3(17.6 \%)$ & .065 & Fisher exact \\
\hline Use of antibiotic powder: $\mathrm{n}(\%)$ & $11(68.8 \%)$ & $6(100 \%)$ & $17(68 \%)$ & $9(52.9 \%)$ & .234 & Fisher exact \\
\hline Use of antibiotic beads: $\mathrm{n}(\%)$ & $2(12.5 \%)$ & $0(0 \%)$ & $3(12 \%)$ & $0(0 \%)$ & .51 & Fisher exact \\
\hline
\end{tabular}

Abbreviation: ANOVA, analysis of variance.

Patients with retention of instrumentation without suppression took an average of 255 days of oral antibiotics (range 7-689 days). Antibiotic regimens are shown in Table 4.

\section{DISCUSSION}

These data aimed to analyze patients with SSI following spinal instrumentation that were assigned to 1 of 4 clinical interventions: implant removal, reinstrumentation, instrument retention with antibiotic suppression, and instrument retention without antibiotic suppression. Patient, infection, surgery, and antibiotic characteristics were obtained to see the emergence of any associations to the final clinical outcome.

Our result demonstrated that none of the patients with retained instrumentation without suppression had recurrence of infections after long-term followup. There is obviously selection bias present in this observation, as the patients taken off of antibiotics were thought to be less likely to have a recurrence of infection. However, it does offer evidence that, in some cases, infected spinal instrumentation can be retained without antibiotic suppression. Although it is hard to definitely state in which cases this lack of suppression is possible, in this series, patients with SSI that present acutely were able to retain their instrumentation after early aggressive debridement. Those with later presentations of infection more likely required removal or exchange of their spinal instrumentation.

The earliest recommendation regarding the optimal antibiotic regimen to treat SSI after spinal instrumentation came from Lonstein ${ }^{22}$ in 1989: 2 weeks of IV antibiotics followed by 3-6 months of oral antibiotics. A more recent study by Kowalski et $\mathrm{al}^{23}$ analyzed 30 early-onset and 51 late-onset spinal implant infections, with the cutoff between early and late being 30 days. They found that early-onset infections could be treated with debridement, antibiotics, and implant retention. Patients with early infection and retained instrumentation took more than 300 days of oral antibiotics. They recommended an oral antibiotic suppression regimen of $>6$ months. A study by Glassman et $\mathrm{al}^{24}$ that included 19 patients with deep infections after surgery for lumbar fusion made very different recommendations. Seventeen of the 19 patients were given a 6-week course of IV antibiotics, and 2 were given a 2-week course of oral antibiotics, and all infections resolved.

Patients in our study who retained implants but were off of suppression had an average of 27 days of IV antibiotics and 255 days of oral antibiotics. Although it is unclear what the lower limit of this suppression should be, Kowalski et $\mathrm{al}^{23}$ did demonstrate the recurrence of symptomatic infection in 5 out of 6 patients who were not given oral suppression therapy for 6 months.

Table 4. Antibiosis characteristics.

\begin{tabular}{|c|c|c|c|c|c|c|}
\hline & $\begin{array}{l}\text { Hardware } \\
\text { Removed }\end{array}$ & Reinstrumented & $\begin{array}{l}\text { Hardware Retained } \\
\text { with Suppression }\end{array}$ & $\begin{array}{l}\text { Hardware Retained } \\
\text { without Suppression }\end{array}$ & $P$ Value & Test \\
\hline Average days of IV antibiotics: $n$ (SD) & $70.4(39.7)$ & $57.5(24.6)$ & $36.8(13.1)$ & $26.6(18.9)$ & $<.001$ & ANOVA $F$ test \\
\hline Average days of oral antibiotics: $n$ (SD) & $283.8(320.7)$ & $378.5(282.2)$ & $737.8(708.4)$ & $254.9(275.6)$ & .012 & ANOVA $F$ test \\
\hline Use of rifampin: $n(\%)$ & $6(32 \%)$ & $4(67 \%)$ & $16(64 \%)$ & $6(37.5 \%)$ & .303 & ANOVA $F$ test \\
\hline Average days without antibiotics: $n$ (SD) & $694.5(982.2)$ & $763(926.2)$ & & $1211.1(844.5)$ & & \\
\hline
\end{tabular}

Abbreviation: ANOVA, analysis of variance. 


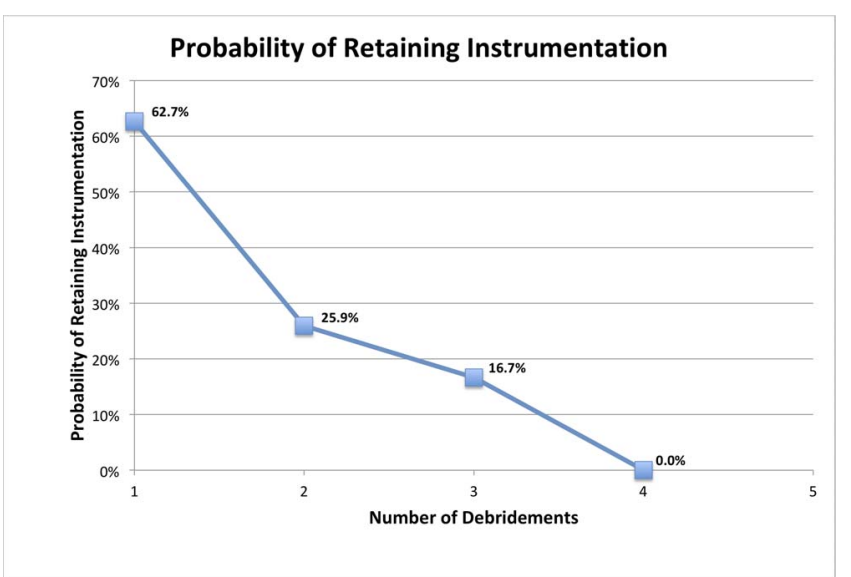

Figure 2. Graphical representation of the probability of retaining instrumentation with each successive surgical debridement.

The use of rifampin is often recommended by ID consultants, as it is thought to have improved efficacy on adherent stationary phase bacteria in biofilms. $^{25}$ In this study, however, the use of rifampin did not significantly impact whether patients were able to retain their instrumentation.

This study also collected data on intraoperative interventions during the surgical debridements to allow for retention of instrumentation. Many of these interventions have good evidence for preventing SSI when utilized during the index operation, such as vancomycin powder ${ }^{26-28}$ and dilute betadine irrigation. ${ }^{29,30}$ However, in our study, none of these interventions were associated with the final clinical outcome.

The most obvious association between the retention of implants that arises from our data is that of the timing of the onset of infection. Onset was defined by the time from the index operation to the time of the first debridement. Similar to the Kowalski et $\mathrm{al}^{23}$ study, infections that presented on average less than 30 days after the index procedure were more likely to be the cases that were treated with retention of instrumentation. Interestingly, these data matches those seen in the arthroplasty literature, where implants with infection in the acute 4-week postoperative period can be retained after a polyethylene liner exchange and thorough debridement. ${ }^{9,10}$

Another association was found between the retention of implants and the presence of a polymicrobial infection. The cohorts with instrumentation removed or exchanged trended toward a higher rate of polymicrobial infections than those with their instrumentation retained $(P=.077)$. This echoes the data found in the total joint literature: polymicrobial infections are associated with a lower rate of clearing infection after a single-stage debridement, two-stage instrumentation exchange, and even resection arthroplasty. ${ }^{12,13}$

There is no strong evidence in the spine literature defining an algorithmic approach to retained infected spinal instrumentation. A balance must be achieved in maintaining stability of the spine and eradicating the nidus of infection. We recognize that these 2 factors may confound the aforementioned findings and add significant selection bias, as instrumentation that was retained or removed may be based less on the infection and more on the stability of the spine.

However, there are preliminary conclusions that can be drawn from these data. First, we believe that lifelong antibiotic suppression may not be required in all cases with infected retained spinal instrumentation. We do recommend a long course of oral antibiotic suppression in such cases; however, the duration is not clear. In this series, infected spinal implants were retained with SSI that present acutely, are not polymicrobial, and were treated with early aggressive debridement. Patients with polymicrobial infections that presented later were more difficult to treat without removal of their original instrumentation.

This study has a number of strengths. Rigorous data collection methodology ensured the accurate collection of a large amount of data from patient charts and notes from various specialties, ensuring the capture of all relevant data. The sample size studied is one of the largest samples of patients with infected spine instrumentation and was collected within the last 10 years, making the results relevant to the contemporary practice of spine surgery. This study also holds the longest length of follow-up for such patients, with the follow-up of patients no longer on antibiotics exceeding an average of 4 years. However, this is a retrospective review, an inherent limitation. Further research is obviously needed, perhaps in the form of a prospective study, to further elucidate the length of antibiotic duration necessary for treating infected spinal instrumentation. More important, further research is necessary to establish clinical guidelines and algorithms for surgically treating SSI with spinal instrumentation.

Our study demonstrated that none of the patients with retained instrumentation without suppression had recurrence of infections after long-term follow- 
up. Therefore, we believe that lifelong antibiotic suppression may not be required for all retained spinal instrumentation. In this series, patients with SSI that present acutely after early aggressive debridement were able to retain their instrumentation. Patients with infections detected later are difficult to treat without removal of their original instrumentation. Although there is significant selection bias in this retrospective study as well as the confounding factor of spinal fusion and stability at the time of surgery, this is an interesting trend that should be further explored. Further research is obviously needed to further elucidate the length of antibiotic duration necessary for treating infected spinal instrumentation and, more importantly, to establish clinical guidelines and algorithms for treating SSI with retained spinal instrumentation.

\section{REFERENCES}

1. Wenzel RP. Health care-associated infections: major issues in the early years of the 21 st century. Clin Infect Dis. 2007;45(suppl 1):S85-S88. https://doi.org/10.1086/518136.

2. Anderson DJ. Surgical site infections. Infect Dis Clin North Am. 2011;25(1):135-153. https://doi.org/10.1016/j.idc. 2010.11.004.

3. McGirt MJ, Godil SS. Reduction of surgical site infection in spine surgery: an opportunity for quality improvement and cost reduction. Spine J. 2013;13(9):1030-1031. https://doi.org/ 10.1016/j.spinee.2013.06.003

4. Broex ECJ, van Asselt ADI, Bruggeman CA, van Tiel FH. Surgical site infections: how high are the costs? J Hosp Infect. 2009;72(3):193-201. https://doi.org/10.1016/j.jhin.2009.03.020.

5. Petilon JM, Glassman SD, Dimar JR, Carreon LY. Clinical outcomes after lumbar fusion complicated by deep wound infection. Spine (Phila Pa 1976). 2012;37(16):13701374. https://doi.org/10.1097/BRS.0b013e31824a4d93.

6. Mok JM, Guillaume TJ, Talu U, et al. Clinical outcome of deep wound infection after instrumented posterior spinal fusion: a matched cohort analysis. Spine (Phila Pa 1976). 2009;34(6):578583. https://doi.org/10.1097/BRS.0b013e31819a827c.

7. Pull ter Gunne AF, Cohen DB. Incidence, prevalence, and analysis of risk factors for surgical site infection following adult spinal surgery. Spine (Phila Pa 1976). 2009;34(13):1422-1428. https://doi.org/10.1097/BRS.0b013e3181a03013.

8. Pull ter Gunne AF, Mohamed AS, Skolasky RL, van Laarhoven CJHM, Cohen DB. The presentation, incidence, etiology, and treatment of surgical site infections after spinal surgery. Spine (Phila Pa 1976). 2010;35(13):1323-1328. https:// doi.org/10.1097/BRS.0b013e3181bcde61.

9. Parvizi J, Gehrke T, Chen AF. Proceedings of the International Consensus on Periprosthetic Joint Infection. Bone Joint J. 2013;95-B(11):1450-1452. https://doi.org/10.1302/0301620X.95B11.33135.

10. Parvizi J, Adeli B, Zmistowski B, et al. Management of periprosthetic joint infection: the current knowledge. $J$ Bone Joint Surg Am. 2012;104(14):1-9. https://doi.org/10.2106/JBJS. K.01417.
11. Kapadia BH, Berg RA, Daley JA, Fritz J, Bhave A, Mont MA. Periprosthetic joint infection. Lancet. 2016;387(10016):386394. https://doi.org/10.1016/S0140-6736(14)61798-0.

12. Lora-Tamayo J, Murillo O, Iribarren JA, et al. A large multicenter study of methicillin-susceptible and methicillinresistant staphylococcus aureus prosthetic joint infections managed with implant retention. Clin Infect Dis. 2013;56(2):182-194. https://doi.org/10.1093/cid/cis746.

13. Marculescu CE, Cantey JR. Polymicrobial prosthetic joint infections: risk factors and outcome. Clin Orthop Relat Res. 2008;466:1397-1404. https://doi.org/10.1007/s11999-0080230-7.

14. Ho C, Skaggs DL, Weiss JM, Tolo VT. Management of infection after instrumented posterior spine fusion in pediatric scoliosis. Spine (Phila Pa 1976). 2007;32(24):2739-2744. https://doi.org/10.1097/BRS.0b013e31815a5a86.

15. Potter BK, Kirk KL, Shah SA, Kuklo TR. Loss of coronal correction following instrumentation removal in adolescent idiopathic scoliosis. Spine (Phila Pa 1976). 2006;31(1):67-72. https://doi.org/10.1097/01.brs.0000192721. 51511.fe.

16. Richards BR, Emara KM. Delayed infections after posterior TSRH spinal instrumentation for idiopathic scoliosis: revisited. Spine (Phila Pa 1976). 2001;26(18):1990-1996. https://doi.org/10.1097/00007632-200109150-00009.

17. Hedequist D, Haugen A, Hresko T, Emans J. Failure of attempted implant retention in spinal deformity delayed surgical site infections. Spine (Phila Pa 1976). 2009;34(1):6064. https://doi.org/10.1097/BRS.0b013e31818ed75e.

18. Viola RW, King HA, Adler SM, Wilson CB. Delayed infection after elective spinal instrumentation and fusion. A retrospective analysis of eight cases. Spine (Phila Pa 1976). 1997;22(20):2444-2451. https://doi.org/10.1097/00007632-19971015000023.

19. Perry JW, Montgomerie JZ, Swank S, Gilmore DS, Maeder K. Wound infections following spinal fusion with posterior segmental spinal instrumentation. Clin Infect Dis. 1997;24(4):558-561.

20. Levi AD, Dickman CA, Sonntag VK. Management of postoperative infections after spinal instrumentation. J Neurosurg. 1997;86(6):975-980. https://doi.org/10.3171/jns.1997.86.6. 0975.

21. Abbey DM, Turner DM, Warson JS, Wirt TC, Scalley RD. Treatment of postoperative wound infections following spinal fusion with instrumentation. $J$ Spinal Disord. 1995;8(4):278-283.

22. Lonstein J. Diagnosis and treatment of postoperative spinal infections. Surg Rounds Orthop. 1989;3:25-32.

23. Kowalski TJ, Berbari EF, Huddleston PM, Steckelberg JM, Mandrekar JN, Osmon DR. The management and outcome of spinal implant infections: contemporary retrospective cohort study. Clin Infect Dis. 2007;44(7):913-920. https:// doi.org/10.1086/512194.

24. Glassman SD, Dimar JR, Puno RM, Johnson JR. Salvage of instrumental lumbar fusions complicated by surgical wound infection. Spine (Phila Pa 1976). 1996;21(18):21632169. https://doi.org/10.1097/00007632-199609150-00021.

25. Zimmerli W, Widmer AF, Blatter M, Frei R, Ochsner PE. Role of rifampin for treatment of orthopedic implantrelated staphylococcal infections: a randomized controlled trial. 
JAMA. 1998;279(19):1537-1541. https://doi.org/10.1001/jama. 279.19.1537.

26. Emohare O, Ledonio CG, Hill BW, Davis RA, Polly DW, Kang MM. Cost savings analysis of intrawound vancomycin powder in posterior spinal surgery. Spine $J$. 2014;14(11):2710-2715. https://doi.org/10.1016/j.spinee.2014. 03.011 .

27. Evaniew N, Khan M, Drew B, Peterson D, Bhandari M, Ghert M. Intrawound vancomycin to prevent infections after spine surgery: a systematic review and meta-analysis. Eur Spine J. 2015;24(3):533-542. https://doi.org/10.1007/s00586-0143357-0.

28. Zebala LP, Chuntarapas T, Kelly MP, Talcott M, Greco $\mathrm{S}$, Riew KD. Intrawound vancomycin powder eradicates surgical wound contamination. J Bone Jt Surg. 2014;96(1):46. https://doi.org/10.2106/JBJS.L.01257.

29. Cheng M-T, Chang M-C, Wang S-T, Yu W-K, Liu C-L, Chen T-H. Efficacy of dilute betadine solution irrigation in the prevention of postoperative infection of spinal surgery. Spine (Phila Pa 1976). 2005;30(15):1689-1693. https://doi.org/10. 1097/01.brs.0000171907.60775.85.

30. Schuster JM, Rechtine G, Norvell DC, Dettori JR. The influence of perioperative risk factors and therapeutic interventions on infection rates after spine surgery: a systematic review.
Spine (Phila Pa 1976). 2010;35(suppl 9):S125-S137. https://doi. org/10.1097/BRS.0b013e3181d8342c.

Disclosures and COI: All authors declare that they have no conflict of interest with the contents of this manuscript. UCSF IRB Approval: 15-16807.

Corresponding Author: Krishn Khanna, MD, Department of Orthopaedic Surgery, University of California, San Francisco, 400 Parnassus Avenue, Third Floor, San Francisco, CA 941430332. Phone: (719) 510-9613; Fax: (415) 353-4047; Email: krishn.khanna@ucsf.edu.

Published 31 August 2018

This manuscript is generously published free of charge by ISASS, the International Society for the Advancement of Spine Surgery. Copyright @ 2018 ISASS. To see more or order reprints or permissions, see http://ijssurgery.com. 